\title{
Determination of virulence and genetic variability of three Spodoptera littoralis nucleopolyhedrovirus isolates from Egypt
}

\author{
Norhan Yasser ${ }^{1}$, Samy Sayed ${ }^{2}$, Nashwa Ghanem³ ${ }^{3}$ Amal Thabit ${ }^{4}$, Aziza Abdelal ${ }^{3}$, Wael Elmenofy ${ }^{5 *}$ and \\ Engy Osman 6
}

\begin{abstract}
Background: The genetic diversity is naturally occurring in baculovirus population, which may affect the potency of the bio-agent. The Spodoptera littoralis nucleopolyhedrovirus is a promising bio-control agent that can be used to control the cotton leafworm, S. littoralis in Egypt. This study described the virulence and genetic variability of $3 \mathrm{~S}$. littoralis nucleopolyhedrovirus isolates named Cab2, P2 and P3 previously recovered from diseased S. littoralis larvae of cabbage, pepper and eggplant cultivation fields.

Results: The viral genomic DNA restriction analysis using Pstl and Scal endonucleases showed identical Pst1 restriction pattern of 10 fragments in both $\mathrm{Cab} 2$ and $\mathrm{P} 3$ isolates, while there are 7 extra fragments present in P2 isolate of about $25,19.8,15,14,11,9$ and 6.7 (kbp). On the other hand, the restriction pattern using Scal revealed 10 common fragments in all three isolates, in addition to an extra marker fragment of about $25 \mathrm{~kb}$ in P3 isolate absent in both P2 and Cab3 isolates. The phylogenetic analysis of the partial nucleotide sequence of the polyhedrin gene confirmed an extensive degree of co-linearity among the genomes of the 3 tested isolates, with pairwise sequence identities of 97.04\% with S. littoralis nucleopolyhedrovirus isolate A26-5 (Acc. No. AY706717). The median lethal concentration $\left(\mathrm{LC}_{50}\right)$ value revealed that $\mathrm{Cab} 2$ had the best virulence toward the first instar of $S$. littoralis larvae with $\mathrm{LC}_{50}$ value of $1.59 \times 10^{4} \mathrm{Obs} / \mathrm{ml}$ compared to the virulence recorded by $\mathrm{P} 3$ and $\mathrm{P} 2$ which were $1.23 \times 10^{6}$ and $2.7 \times 10^{4} \mathrm{OBs} / \mathrm{ml}$, respectively. The median survival time $\left(\mathrm{LT}_{50}\right)$ value of $\mathrm{Cab} 2$ isolate was the highest speed of treated larval mortality with 120 hpi compared to P2 and P3, which recorded 132 hpi for both isolates.
\end{abstract}

Conclusions: Although all three S. littoralis nucleopolyhedrovirus isolates showed considered genotypic variation and insecticidal activity against $S$. littoralis larvae, the variant Cab2 showed the highest virulence and speed mortality against the first instar larvae of $S$. littoralis. The new variant proved to possess promising insecticidal properties for the development of virus-based biopesticide for the control of $S$. littoralis population in Egypt.

Keywords: Spodoptera littoralis NPV, Genetic diversity, Virulence parameters, Phylogenetic analysis

\section{Background}

The cotton leafworm, Spodoptera littoralis (Lepidoptera: Noctuidae), causes huge damage to different strategic crops and vegetables in Egypt and worldwide. Due to the

\footnotetext{
*Correspondence: wael.elmenofy@ageri.sci.eg

${ }^{5}$ Agricultural Genetic Engineering Research Institute, Agricultural

Research Center, Giza 12619, Egypt

Full list of author information is available at the end of the article
}

negative impact of chemical insecticides that had led to the exploration of alternative control measures such as bacteria, fungi and viruses as an environmentally friendly bio-control agents as an active ingredient in many commercial products (Lei et al. 2020), baculoviruses have been considered as potent pathogens of insects, specifically lepidopteran pests that attack different economic crops (Sahayaraj et al. 2018). Baculoviruses (family: Baculoviridae) have been characterized as rod-shaped 
enveloped viruses with a circular double-strand DNA genome of molecular weight ranged from 80 to 180 kilo basepair (kbp) (Hill and Unckless 2017). Taxonomically, the Baculoviridae family is classified into two genera, Granulovirus (GV) and Nucleopolyhedrovirus (NPV) relying on the morphology of the occlusion bodies (obs) (Rohrmann 2008). Based on baculovirus genomes DNA sequences, a new classification was proposed as follows: Alphabaculovirus: lepidopteran NPVs; Betabaculovirus: lepidopteran GVs; Gammabaculovirus: hymenopteran NPVs and Deltabaculovirus: dipteran NPVs (Herniou et al. 2011). Naturally, baculoviruses are thought to control the size of insect populations, and this is the basis for their application as a bio-control agent of pests (Moscardi 1999). Baculovirus is considered as an outstanding candidate biopesticide due to its specificity, safe to vertebrates and plants with no negative impacts on non-target insects, still present some obstacles to be utilized commercially, as slow killing speed and narrow spectrum of its activity as well as short stability in the field (RegnaultRoger 2012). Therefore, using novel viral isolates as a candidate for the development of biopesticide against the $S$. littoralis population may be important to overcome those obstacles. Nevertheless, picking native virus isolates to be utilized as a bio-control agent requires molecular and biological characterization of the isolate present in each geographical area (Herniou and Jehle 2007).

The present study described the virulence and genetic variability of SpliNPV isolates, which were collected from naturally NPV-infected larvae from cultivars of eggplant, pepper and cabbage in Egypt.

\section{Methods}

\section{Insect}

Neonates of the cotton leafworm, S. littoralis were used for the bioassay analyses and fourth instar larvae were used for virus propagation. The colony was maintained in growth chamber at $26 \pm 1{ }^{\circ} \mathrm{C}$ and $70-80 \%$ R.H., and 16:8 light/dark photoperiods. Larvae were reared on a semi-synthetic diet according to Levinson and Navon (1969), which contains agar-agar mixed with ascorbic acid, ground kidney bean, Brewer's yeast and methyl-4-hydroxybenzoate.

\section{Viruses' purification and propagation}

NPV isolates were from the infected $S$. littoralis larvae collected from eggplant, pepper and cabbage crops from different locations in Egypt. Collected larvae were individually kept at $-20{ }^{\circ} \mathrm{C}$ in $15-\mathrm{ml}$ plastic tubes. In order to prepare larvae for an initial phase-contrast microscopic examination and for virus propagation, they were homogenized individually in $\mathrm{ddH}_{2} \mathrm{O}$ and centrifuged at $100 \times g$ for 3-5 min. to remove cell debris. Then, the supernatant was centrifuged at $5000 \times g$ for $10 \mathrm{~min}$ to facilitate OBs precipitation. The pelleted OBs were re-suspended in suitable amount of $d d \mathrm{H}_{2} \mathrm{O}$. Small amount of OBs was examined under a phase-contrast microscope. Purified OBs for each isolate were used to inoculate about fifty fourth instar larvae by feeding them a small piece of medium contaminated with few microliters of each isolate for $24 \mathrm{~h}$. Next day, larvae that ingested the viral-contaminated medium were transferred to a fresh medium. The infected larvae were maintained under controlled ambient conditions, and the dead larvae were collected few days post-infection (p.i.) and subjected for OBs purification. For the purification of viral OBs, the individually dead larvae showing symptoms of viral infection were homogenized in $0.1 \%$ aqueous sodium dodecyl sulfate (SDS) (w/v) (1 ml /larva), filtered through two layers of cheese cloth and one of cotton several times to get rid from insect debris. The resulting pellets were washed in $0.5 \mathrm{M} \mathrm{NaCl}$ followed by re-suspension in sterile $\mathrm{ddH}_{2} \mathrm{O}$ $\left(0.5 \mathrm{ml} /\right.$ larva) and stored at $-20{ }^{\circ} \mathrm{C}$. The concentration of the purified OBs was determined using the dark field of Ziss Axiovert A1 light microscope with 200X magnification using a Petroff Hausser counting chamber (depth $0.01 \mathrm{~mm}$ ) as previously described (Jehle et al. 1992).

\section{Virus restriction pattern}

The genomic DNA of viral isolates was purified from viral polyhedra of each isolate according to Boughton et al. (1999). Briefly, $200 \mu \mathrm{l}$ of viral OBs of each isolate was precipitated for $5 \mathrm{~min}$ at $8000 \mathrm{rpm}$, and the pellet re-suspended in $200 \mu \mathrm{l}$ of $\mathrm{dd}_{2} \mathrm{O}$. Using $1 \mathrm{M} \mathrm{Na}_{2} \mathrm{CO}_{3}$, the samples were treated in the final concentration of $0.1 \mathrm{M}$ and then incubated at $37^{\circ} \mathrm{C}$ for $1 \mathrm{~h}$ until the solution became almost clear. One millimolar $\mathrm{HCl}$ was used to neutralize the solution to $\mathrm{pH} 8$ before adding SDS in a final concentration of $1 \%$. Then, proteinase $\mathrm{K}$ was added in a final concentration of $250 \mu \mathrm{g} / \mathrm{ml}$, and the suspension was incubated for $1 \mathrm{~h}$ at $37{ }^{\circ} \mathrm{C}$ to release viral genomic DNA. The samples were treated with phenol/ chloroform 1:1 $(\mathrm{v} / \mathrm{v})$ and once with chloroform to remove the phenolic residues. Using $1 / 10$ volumes $3 \mathrm{M} \mathrm{NaAc} \mathrm{pH}$ 5.2 and 2.5 volume ice-cold $96 \%$ ethanol DNA was precipitated in $-20{ }^{\circ} \mathrm{C}$ overnight and then washed using $70 \%$ ethanol. The obtained genomic DNA was dried for $5 \mathrm{~min}$, and subsequently, DNA was eluted in enough amount of ddH2O.

Restriction endonuclease (REN) analysis was performed for each isolate by digestion of $1.5 \mu \mathrm{g}$ of genomic DNA using 10U of PstI, and SacI endonucleases (Thermo Fisher) at $37^{\circ} \mathrm{C}$ for $2 \mathrm{~h}$. The obtained restriction fragments were electrophoresed on a $0.8 \%$ agarose gel at $30 \mathrm{~V}$ overnight using TAE buffer $(1 \mathrm{mM}$ 
EDTA, $40 \mathrm{mM}$ Tris-acetate at $\mathrm{pH}$ 8.0), stained with SYBR Safe (Thermo Fisher) and then visualized under UV-Transilluminator.

PCR amplification and sequencing of polyhedrin gene One pair of specific primers named Spli-polh-F (5-ATC TGGGCAAAACCTATGTAT-3) and Spli-polh-R (CTT GGCGAGACTGATGCGGTATTC) were designed, synthesized and used for amplification of polyhedrin gene fragment using purified viral DNA according to the method described recently by Elmenofy et al. (2020). Blastn was used to align the nucleotide sequences of the three isolates against the NCBI reference nucleotide database. MEGA-X was used for multiple alignments and producing tree data. The tree data clustering method was neighbor joining, and iTOL was used to create the phylogenetic tree.

\section{Insecticidal activity of virus isolates}

Insecticidal activity was performed in autoclavable 50 -well plates containing $45 \mathrm{ml}$ of semi-synthetic diet mixed with $5 \mathrm{ml}$ virus suspension. The median lethal concentration (LC50) was determined using six different OB concentrations in each ml medium using viral concentration stock of $2.9 \times 10^{8} \mathrm{OBs} / \mathrm{ml}$. The concentrations were prepared as follows: $10^{3}, 5 \times 10^{3}, 10^{4}, 5 \times 10^{4}, 10^{5}$, $5 \times 10^{5}$ and $10^{6} \mathrm{OBs} / \mathrm{ml}$ as well as two virus-free plates as control. Fifty larvae were used for each concentration of virus isolate as well as the control, which mixed with $\mathrm{ddH} 2 \mathrm{O}$ instead of virus suspension. Each bioassay was replicated three times. Mortality was recorded at day one post-infection, to exclude those larvae which died from handling, and after 7 days. The mean survival time (ST50) was determined by inoculating 50 larvae in two independent replicates with the calculated LC85 for each tested virus isolate, as well as two control plates. Mortality of the larvae was monitored daily and every $12 \mathrm{~h}$ starting at day 3 post-infection until day 10 or larval death.

\section{Statistical analysis}

Estimation of the LC50 and slopes of regression lines were calculated by probit analysis according to Finney (1971) using EPA probit analysis program version 1.5 package. Significance testing of the LC50 was done by pairwise comparisons using non-overlapping 95\% confidence intervals (CIs) (Robertson and Preisler 1992). The ST50 value was determined using the Kaplan-Meier estimator analysis method (Kaplan-Meier, 1958), and the GraphPad Prism version 6.04 for Windows, GraphPad Software, La Jolla California USA, www.graphpad.com

\section{Results}

\section{Restriction profile analysis}

The genomic DNA of each of the three SpliNPV isolates was digested using the enzymes $S c a \mathrm{I}$ and Pst to compare restriction profiles generated among them (Fig. 1). The analysis was carried out by counting the number of extra fragments present in proportion to the number of fragments produced by each digestion that were common to all isolates. Some new DNA fragments were observed among the restriction profiles of each viral isolate, particularly for digestion with PstI that revealed an even greater range of variation in terms of number of detectable DNA fragments (7 fragments). Cab2 and P3 isolates showed identical Pst1 restriction profile of 10 fragments, while there are 7 extra submolar fragments present only in P2 of about 25, 19.8, 15, 14, 11, 9 and 6.7 (kbp). However, the restriction profile of ScaI revealed 10 common fragments in the three isolates, and an extra marker fragment of about $25 \mathrm{~kb}$ in P3 isolate absent in P2 and Cab3.

\section{Phylogenetic analysis}

Enough amount of genomic DNA was successfully purified from each isolate and used along with two oligonucleotide primers, which were designed to amplify partial fragment within the polyhedrin gene. Since these primers are highly conserved amongst NPVs, they were employed in the present study for Egyptian NPVs detection and identification by PCR as well as phylogenetic analysis (Jehle et al. 2006). The results showed that the PCR-amplified fragments gave the expected size of polh gene of about 494 bp (data nor shown), which subsequently subjected to Sanger nucleotide sequencing to be compared to other NPVs corresponding to sequences available in NCBI GenBank. Alignment of Cab2, P2 and P3 isolates with polyhedrin gene sequences of other NPV isolates confirmed an extensive degree of co-linearity among the genomes of these NPVs, with pairwise sequence identities of $97.04 \%$ with S. littoralis nucleopolyhedrovirus isolate A26-5 (Acc. No. AY706717) (Fig. 2).

\section{Bioassay}

The median lethal concentration (LC50) of Cab2, P2 and P3 isolates was determined to test their virulence on $S$. littoralis larvae. Based on LC50 values (Table 1), the LC50 values of Cab2, P2 and P3 were $1.59 \times 10^{4}, 1.23 \times 10^{6}$ and $2.7 \times 10^{4} \mathrm{OBs} / \mathrm{ml}$, respectively. The results revealed that Cab2 had the best virulence based on larval mortality than the lowest virulence recorded by P3 and P2. Using the Kaplan-Meier survival time estimator analysis, the ST50 was calculated (Table 2). The calculated ST50 values were $120 \mathrm{~h}$ for Cab2, $132 \mathrm{~h}$ for P2 and $132 \mathrm{~h}$ for P3. 


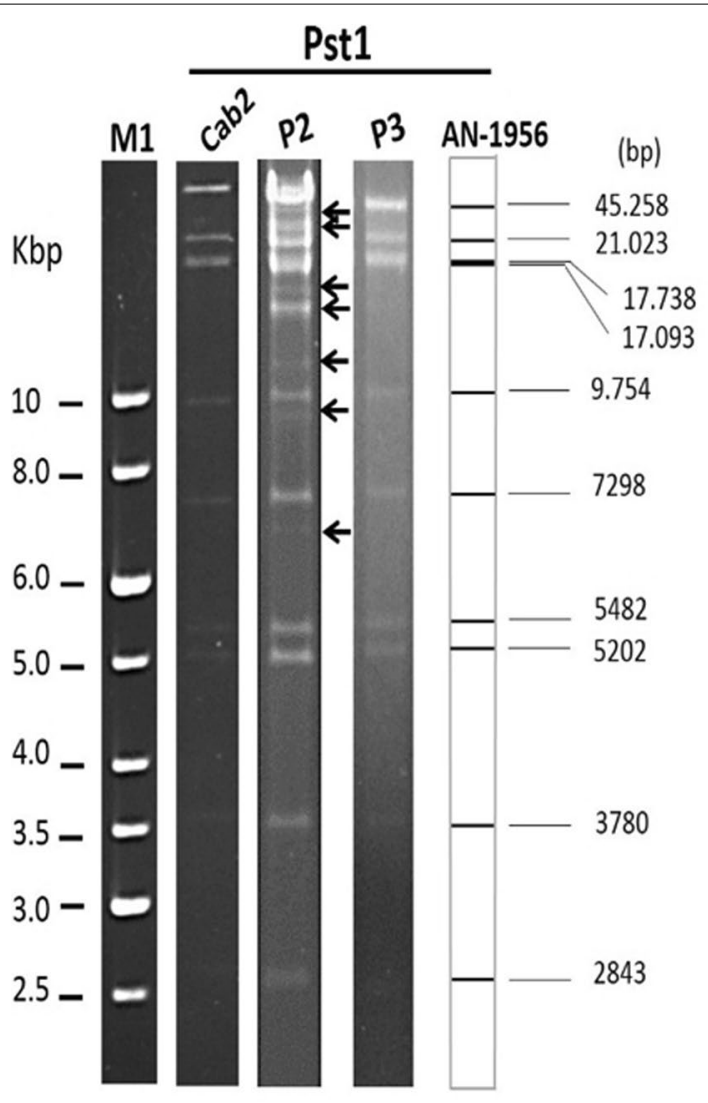

(A)

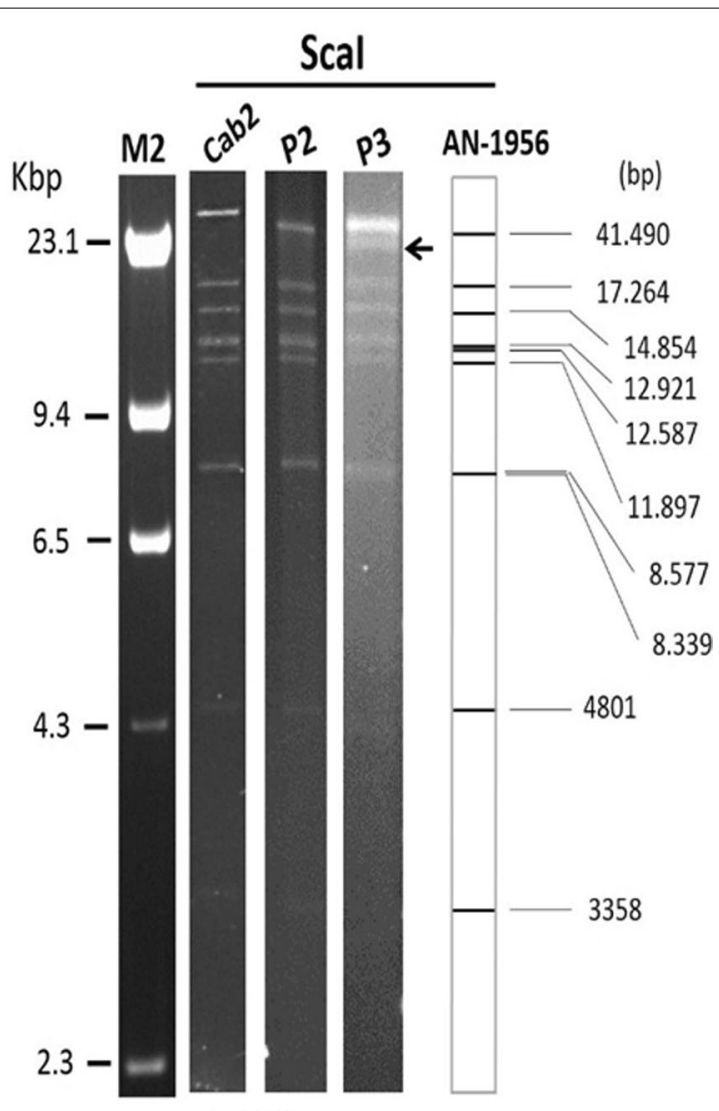

(B)

Fig. 1 Restriction endonuclease analysis of viral genomic DNA purified from Cab2, P2 and P3 isolates. A Restriction profile analysis of all isolates generated by Pstl endonuclease. B Restriction profile analysis of all isolates generated by Scal endonuclease. Electrophoresis was generated on a 0.8\% agarose gel for 18 hr using 30 V. M1: 1 kb DNA ladder (Thermo Fisher), M2: Lambda Hindlll DNA ladder (Thermo Fisher). Arrows indicated submolar bands among isolates

These results showed that Cab2 isolate was the highest speed of treated larval mortality compared to P2 and P3 isolates with about $12 \mathrm{~h}$.

\section{Discussion}

In this study, three SpliNPV isolates were derived from $S$. littoralis-infected larvae from cultivated field of cabbage, pepper and eggplant crops in different districts in Egypt. Their DNA were purified and subjected to REN analysis. Results of the REN analyses showed that all three isolates, Cab2, P2 and P3, exhibited slightly different number and pattern of gel fragments demonstrating the existence of genetic differences among them. The difference in the three SpliNPV isolate profiles demonstrated that the isolates comprised genotypic variants in different proportions. Hence, the variations in the genomes of baculoviruses could result in relative difference in their virulence and pathogenicity (Behle and Popham 2012).

Previously, REN analysis was performed on nine SpltNPV isolates from sick Spodoptera litura and an Egyptian isolate of Spodoptera littoralis NPV. Six of the ten isolates had new submolar bands, which indicated a combination of genotypes (Takatsuka et al. 2003). Cherry and Summers (1985) investigated the genetic diversity of NPVs that infected S. littoralis and also discovered two different viruses, SpliNPV-A and SpliNPV-B, which were equally dispersed throughout Israel. In addition, REN profile analysis of SpliNPV Egyptian isolates named $\mathrm{Cab}-3$ and Spli-7 showed a number of submolar bands where these isolates comprised genotypic variants (Elmenofy et al. 2020).

The NPV isolates in the current study showed a significant homology with $100 \mathrm{NPV}$ isolates based on GenBank database. They showed $93.1 \%$ identity with $S$. littoralis NPV polyhedrin gene of both SpliNPV-Tun2 and SpliNPV-AN1956 strains under accession number of MG958660.1 and NC_038369.1, respectively, which were isolated from Tunisia and Egypt.

Bioassays of the Cab2, P2 and P3 in this study revealed a distinct pattern of virulence among them. The variant 


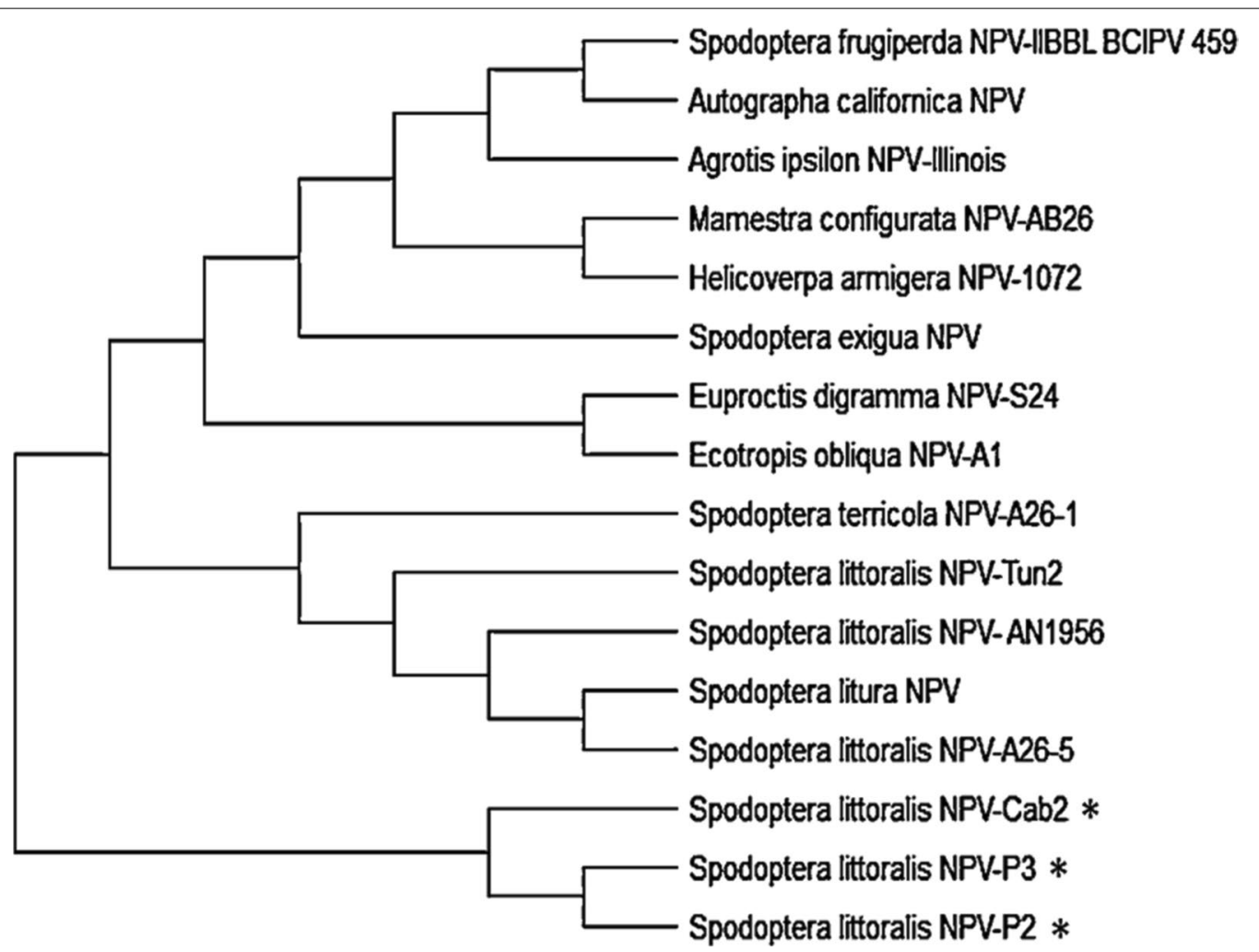

Fig. 2 Phylogenetic inference of relationships among isolates of NPV based on polyhedrin nucleotide sequence alignments. The evolutionary history was inferred using the neighbor-joining method. The SpliNPV isolates Cab2, P2 and P3 are indicated by black asterisks

Table 1 Bioassay of Spodoptera littoralis nucleopolyhedrovirus against the first instar S. littoralis larvae

\begin{tabular}{llcccc}
\hline Isolate code & LC $\mathbf{5 0}(\mathbf{O B s} / \mathbf{m l})$ & Fiducial limit lower & Fiducial limit upper & $\mathbf{X}^{\mathbf{2}}$ & Slope \\
\hline Cab2 & $1.59 \times 10^{4}$ & 3535.124 & $35,210.320$ & 9.4 & 1.57 \\
P2 & $1.23 \times 10^{6}$ & $629,259.875$ & $4,419,055.500$ & 11.07 & 0.76 \\
P3 & $2.7 \times 10^{4}$ & $17,298.635$ & $43,715.742$ & 9.48 & 1.36 \\
\hline
\end{tabular}

Table 2 ST50 values of the first instar Spodoptera littoralis larvae infected by S. littoralis NPVS

\begin{tabular}{|c|c|c|c|c|c|}
\hline Isolate code & No. of larvae & LC 85 (OBs/ml) & Fiducial limit lower & Fiducial limit upper & ST50 \\
\hline Cab2 & 103 & $72,542.555$ & $32,927.668$ & $362,103.844$ & 120 \\
\hline P2 & 120 & $27,950,752$ & $6,763,316$ & $570,543,168$ & 132 \\
\hline P3 & 107 & $156,760.688$ & $88,530.328$ & $380,817.656$ & 132 \\
\hline
\end{tabular}

Cab2 presented a high virulence on the first instar larvae of S. littoralis with LC50 value of $1.59 \times 10^{4} \mathrm{OB} / \mathrm{ml}$, than the P2 and P3 variants that represent lower LC50 value of $1.23 \times 10^{6}$ and $2.7 \times 10^{4} \mathrm{OBs} / \mathrm{ml}$, respectively. Moreover, it was shown that Cab2 was faster to kill the larvae with ST50 value of $120 \mathrm{~h}$ compared to both other isolates P2 and P3, which showed ST50 value of $132 \mathrm{~h}$ for both isolates.

The selection of native isolates is crucial for developing a virus-based insecticide against $S$. littoralis. Elmenofy et al. (2020) studied a new field collected from SpliNPV-Cab3 genotypic variant to determine 
its toxic effect against $S$. littoralis, as a novel, environmentally safe candidate virus-based bioinsecticide. SpliNPV-Cab3 indigenous isolate was identified as a variation isolate of the reference strain SpliNPVAN1956 based on the REN pattern and phylogenetic analysis.

The virulence parameters of the three NPV isolates of the current study showed that the LC50 values were higher than the LC50 observed for the first instar S. littoralis of some SpliMNPV isolates presented by Toprak et al. (2005). The LC50 value of both Cab2 and P3 $\left(1.59 \times 10^{4}\right.$ and $\left.2.7 \times 10^{4} \mathrm{OBs} / \mathrm{ml}\right)$ was slightly higher than the calculated LC50 values for the $S$. littoralis first instar using Spli- 6 and Spli-7 isolates $\left(3 \times 10^{4}\right.$ and $9.5 \times 10^{4} \mathrm{OBs} / \mathrm{ml}$, respectively) that was studied by Elmenofy et al. (2020). On the other hand, the speed of mortality by both isolates Spli-6 and Spli-7 based on ST50 value was $96 \mathrm{~h}$, which showed to be faster than that the current isolates Cab2, P2 and P3 against S. littoralis larvae with ST50 values of 120, 132 and $132 \mathrm{~h}$ for the three isolates, respectively. On the other hand, the ST50 value of the isolates under the current study was less than the ST50 value for SpliMNPV isolates calculated by Lacey et al. (2015), which ranged from 125 to $360 \mathrm{~h}$. Hence, the genetic variations observed in SpliNPV isolates Cab2, P2 and P3 might have influenced the viral potency of $S$. littoralis larvae.

The variability of LC50 and ST50 is probably due to different factors such as the technique of surface treatment, homogeneously treated diet and feeding habit of the insect species or due to difference in larval instars. It might possibly be also related to differences in the host's sensitivity to NPV isolates, the total number of virions for each $\mathrm{OB}$, the virus strain's pathogenicity and/or the cycles used for the viral isolate propagation (Seufi 2008).

Therefore, the development of novel and environmentally safe alternatives has become an urgent need for integrated control programs for the cotton leafworm, with emphasis on biological control through entomophagous plant extracts and microorganisms (Matloub et al. 2021).

Based on the virulence characteristics (LC50 and ST50) of the three isolates described in this study, their potential as a promising viral-based bioinsecticide is suggested, specially isolate $\mathrm{Cab} 2$, which showed the best virulence values against $S$. littoralis larvae. As long as baculoviruses are isolated in Egypt from different districts, it is expected to discover much more virus isolates in virgin districts where no chemical pesticides are used. These observations suggested that the Egyptian environment is suitable for not only gathering novel baculovirus isolates but also for their potential use as viral-based pesticides in integrated pest management schemes (IPM).

\section{Conclusions}

In the current study, three SpliNPV isolates named Cab2, P2 and P3 were isolated from dead larvae of S. littoralis and characterized. The restriction profile analysis showed the presence of genotypic variations among viral isolates. The phylogenetic analysis based on polyhedrin nucleotide sequences confirmed an extensive degree of colinearity among the genomes of the three virus isolates. Furthermore, Cab2 isolate showed the best virulence values against the first instar larvae of $S$. littoralis based on the calculated LC50 and ST50 values, compared to P2 and P3 isolates. These results suggested the potential utilization of Cab2 variant as a base for the development of viral-based bioagent for the effective control of S.littoralis population in Egypt.

\section{Abbreviations}

SpliNPV: Spodoptera littoralis Nucleopolyhedrovirus; OBs: Occlusion bodies: $\mathrm{LC}_{50}$ : Median lethal concentration; $\mathrm{ST}_{50}$ : Median survival time; h: Hours; Min: Minute; hpi: Hours post-infection; REN: Restriction endonuclease; OBs: Occlusion bodies.

\section{Acknowledgements \\ Not applicable.}

\section{Authors' contributions}

WE conceived the idea and designed the study. NY and EO performed wet laboratory experimentation. SS and WE provided technical and financial assistance for the study. NG and AT did the virus counting, propagation and purification. NY wrote the first draft of the manuscript. NY and AA did the insect rearing, the bioassay experiments in addition to the statistical analysis. WE and SS technically proofread the manuscript. All authors read and approved the final manuscript.

\section{Funding}

This study was funded by the Academy of Scientific Research \& Technology (Project ID: 1490). This funder provided chemicals, reagents and kits used in this study. Also, this study was financed by Taif University Researchers Supporting Project number (TURSP -2020/92), Taif university, Taif, Saudi Arabia. This funder provided materials used for insect rearing and virus propagation, bioassays, nucleotide sequencing and oligos synthesis used for PCR.

\section{Availability of data and materials}

All data generated or analyzed in this work are available in the published manuscript.

\section{Declarations}

Ethics approval and consent to participate Not applicable.

\section{Consent for publication}

This study does not contain any individual person's data.

\section{Competing interests}

The authors declare not to have any competing interests regarding the publication of this work.

\section{Author details}

${ }^{1}$ Faculty of Biotechnology, October University for Modern Sciences and Arts, 6th of October City, Giza, Egypt. ${ }^{2}$ Department of Science and Technology, University College-Ranyah, Taif University, B.O. Box 11099, Taif 21944, Saudi Arabia. ${ }^{3}$ Agricultural Research Center, Plant Protection Research Institute, Dokki, Giza 12311, Egypt. ${ }^{4}$ Faculty of Graduate Studies and Environmental Research, 
Ain Shams University, El-Abaseya, Egypt. ${ }^{5}$ Agricultural Genetic Engineering Research Institute, Agricultural Research Center, Giza 12619, Egypt. ${ }^{6}$ Faculty of Agriculture, Cairo University, 9 Gamaa St., Giza 12619, Egypt.

Received: 31 October 2021 Accepted: 10 February 2022

Published online: 17 February 2022

\section{References}

RW Behle HJ Popham 2012 Laboratory and field evaluations of the efficacy of a fast-killing baculovirus isolate from Spodoptera frugiperda J Invert Pathol 109194200

AJ Boughton RL Harrison LC Lewis BC Bonning 1999 Characterization of a nucleopolyhedrovirus from the black cutworm, Agrotis ipsilon (Lepidoptera: Noctuidae) J Invert Pathol 74289294

CL Cherry MD Summers 1985 Genotypic variation among wild isolates of two nuclear polyhedrosis viruses isolated from Spodoptera littoralis I Invert Pathol 46289295

W Elmenofy R Salem E Osman N Yasser A Abdelmawgod M Saleh A Zaki 2020 Evaluation of two viral isolates as a potential biocontrol agent against the Egyptian cotton leafworm, Spodoptera littoralis (Boisd.)(Lepidoptera: Noctuidae) Egypt J Biol Pest Control 3018

DJ Finney 1971 Probit analysis 3 Cambridge University Press Cambridge

EA Herniou JA Jehle 2007 Baculovirus phylogeny and evolution Curr Drug Targets 810431050

EA Herniou BM Arif JJ Becnel GW Blissard B Bonning R Harrison JA Jehle DA Theilmann JM Vlak 2011 Baculoviridae AMQ King MJ Adams EB Carstens EJ Lefkowitz Eds Virus taxonomy Elsevier Oxford 163174

T Hill RL Unckless 2017 The dynamic evolution of Drosophila innubila Nudivirus Infect Genet Evol 57151157

JA Jehle H Backhaus E Fritsch J Huber 1992 Physical map of Cryptophlebia leucotreta granulosis virus genome and its relationship to the genome of Cydia pomonella granulosis virus J Gen Virol 7316211626

JA Jehle M Lange H Wang Z Hu Y Wang R Hauschild 2006 Molecular identification and phylogenetic analysis of baculoviruses from Lepidoptera Virology 346180193

LA Lacey D Grzywacz DI Shapiro-llan R Frutos M Brownbridge MS Goettel 2015 Insect pathogens as biological control agents: back to the future J Invert Pathol 132141

C Lei J Yang J Wang J Hu X Sun 2020 Molecular and biological characterization of Spodoptera frugiperda multiple nucleopolyhedrovirus field isolate and genotypes from China Insects 11777

H Levinson A Navon 1969 Ascorbic acid and unsaturated fatty acids in the nutrition of the Egyptian cotton leafworm Prodenia litura J Insect Physiol 15591595

A Matloub A Maamoun N Abdel-Aziz E Samour H El-Rafie 2021 Eco-friendly secondary metabolites from Conyza dioscoridis against Spodoptera littoralis Egypt J Chem 64341357

F Moscardi 1999 Assessment of the application of baculoviruses for control of Lepidoptera Annu Rev Entomol 44257289

Regnault-Roger C (2012) Trends for commercialization of biocontrol agent (biopesticide) products. In Plant defense: biological control. Springer, Dordrecht, pp 139-160

JL Robertson HK Preisler 1992 Pesticide bioassay with arthropods CRC Press Boca Raton

Rohrmann GF (2008) Baculovirus molecular biology. National Library of Medicine, National Center for Biotechnology Information, Bethesda, MD

K Sahayaraj N Subash RW Allingham V Kumar PB Avery LK Mehra LS Osborne 2018 Lethal and sublethal effects of three microbial biocontrol agents on Spodoptera litura and its natural predator Rhynocoris kumarii Insects 9101

AM Seufi 2008 Characterization of an Egyptian Spodoptera littoralis nucleopolyhedrovirus and a possible use of a highly conserved region from polyhedrin gene for nucleopolyhedrovirus detection Virol J 5111

J Takatsuka S Okuno M Nakai Y Kunimi 2003 Genetic and biological comparisons of ten geographic isolates of a nucleopolyhedrovirus that infects Spodoptera litura (Lepidoptera: Noctuidae) Biol Control 263239

U Toprak S Bayram MO Gürkan 2005 Gross pathology of SpliNPVs and alterations in Spodoptera littoralis Boisd. (Lepidoptera: Noctuidae) morphology due to baculoviral infection Tarim Bilimleri Dergisi 116571

\section{Publisher's Note}

Springer Nature remains neutral with regard to jurisdictional claims in published maps and institutional affiliations.

\section{Submit your manuscript to a SpringerOpen ${ }^{\circ}$ journal and benefit from:}

- Convenient online submission

- Rigorous peer review

- Open access: articles freely available online

- High visibility within the field

- Retaining the copyright to your article

Submit your next manuscript at $\boldsymbol{\nabla}$ springeropen.com 